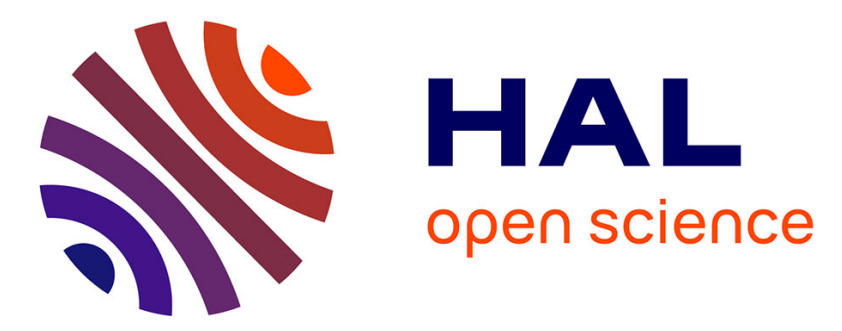

\title{
Oxygen broadening and shift coefficients in the $\nu 6$ band of methyl iodide (12CH3I) at room temperature
}

Y. Attafi, S. Galalou, F. Kwabia Tchana, J. Vander Auwera, A. Ben Hassen, H. Aroui, Agnès Perrin, L. Manceron, D. Doizi

\section{- To cite this version:}

Y. Attafi, S. Galalou, F. Kwabia Tchana, J. Vander Auwera, A. Ben Hassen, et al.. Oxygen broadening and shift coefficients in the $\nu 6$ band of methyl iodide (12CH3I) at room temperature. Journal of Quantitative Spectroscopy and Radiative Transfer, 2019, 239, pp.106679. 10.1016/j.jqsrt.2019.106679 . hal-02341270

\author{
HAL Id: hal-02341270 \\ https://hal.science/hal-02341270
}

Submitted on 31 Oct 2019

HAL is a multi-disciplinary open access archive for the deposit and dissemination of scientific research documents, whether they are published or not. The documents may come from teaching and research institutions in France or abroad, or from public or private research centers.
L'archive ouverte pluridisciplinaire HAL, est destinée au dépôt et à la diffusion de documents scientifiques de niveau recherche, publiés ou non, émanant des établissements d'enseignement et de recherche français ou étrangers, des laboratoires publics ou privés. 


\section{Oxygen broadening and shift coefficients in the $v_{6}$ band of methyl iodide $\left({ }^{12} \mathrm{CH}_{3} \mathrm{I}\right)$ at room temperature}

Y. Attafi, ${ }^{a, b}$ S. Galalou ${ }^{b}$, F. Kwabia Tchana,${ }^{a^{*}}$ J. Vander Auwera, ${ }^{c}$ A. Ben Hassen, ${ }^{b}$ H. Aroui, ${ }^{b}$ A. Perrin ${ }^{\mathrm{d}}$, L. Manceron, ${ }^{\mathrm{e}, \mathrm{f}}$ D. Doizi ${ }^{\mathrm{g}}$

${ }^{a}$ Laboratoire Interuniversitaire des Systèmes Atmosphériques (LISA), UMR CNRS 7583, Université de Paris et Université Paris Est Créteil, Institut Pierre Simon Laplace (IPSL), 61 avenue du Général de Gaulle, F-94010 Créteil Cedex, France.

${ }^{\mathrm{b}}$ Laboratoire de Spectroscopie et Dynamique Moléculaire, Université de Tunis, Ecole Nationale Supérieure d'Ingénieurs de Tunis, 5 Av Taha Hussein, 1008 Tunis, Tunisia.

${ }^{\mathrm{c}}$ Service de Chimie Quantique et Photophysique, C.P. 160/09, Université Libre de Bruxelles, 50 avenue F.D. Roosevelt, B-1050 Brussels, Belgium.

${ }^{d}$ Laboratoire de Météorologie Dynamique/IPSL, UMR CNRS 8539, Ecole Polytechnique, Université Paris-Saclay, RD36, F-91128 PALAISEAU Cedex, France.

${ }^{\mathrm{e}}$ Ligne AILES, Synchrotron SOLEIL, L'Orme des Merisiers, St-Aubin BP48, F-91192 Gifsur-Yvette Cedex, France.

${ }^{\mathrm{f}}$ Sorbonne Université, CNRS, MONARIS, UMR 8233, 4 place Jussieu, F-75005 Paris,France

${ }^{g}$ DEN-Service d'Etude du Comportement des Radionucléides (SECR), CEA, Université Paris-Saclay, F-91191 Gif-sur-Yvette, France

$\mathrm{Nb}$ of figures: 11

$\mathrm{Nb}$ of Tables: 4

*Corresponding author: Fridolin Kwabia Tchana, fridolin.kwabia@lisa.u-pec.fr 


\section{Abstract}

In this study we report the high-resolution measurements of oxygen pressurebroadening and pressure-induced shift coefficients for rovibrational transitions in the $v_{6}$ band of methyl iodide $\left({ }^{12} \mathrm{CH}_{3} \mathrm{I}\right)$, centered at $892.918 \mathrm{~cm}^{-1}$. The results were obtained by analyzing fourteen high-resolution room temperature laboratory absorption spectra with a monospectrum non-linear least squares fitting of Voigt profiles. The data were recorded with the Bruker IF125HR Fourier transform spectrometer located at the LISA facility in Créteil, using a White type cell with a path length of $564.9 \mathrm{~cm}$ and total pressures up to $295 \mathrm{hPa}$. The measured oxygen-broadening coefficients range from 0.0648 to $0.1207 \mathrm{~cm}^{-1} \mathrm{~atm}^{-1}$ at $295 \mathrm{~K}$. The measured shift coefficients were all negative and varied between -0.00044 and -0.04984 $\mathrm{cm}^{-1} \mathrm{~atm}^{-1}$. The average accuracy on the measured $\mathrm{O}_{2}$-broadening coefficients and pressure shift coefficients was estimated to about $4 \%$ and $11 \%$, respectively. The $\mathrm{O}_{2}$-broadening coefficients results obtained in the present work are compared with other values reported in the literature for the $v_{5}$ band of $\mathrm{CH}_{3} \mathrm{I}$, showing a satisfactory agreement with an average difference of about $8 \%$. The shift coefficients are compared with the values reported in the literature for the $v_{6}$ band of $\mathrm{CH}_{3} \mathrm{~F}-\mathrm{Ar}$ system and show the same order of magnitude and trend. The $J$ and $K$ rotational dependences of the $\mathrm{O}_{2}$-broadening coefficients have been observed and the latter modeled using empirical polynomial expansions. On average, the empirical expression reproduces the measured $\mathrm{O}_{2}$-broadening coefficients to within $3 \%$. Using the measured broadening coefficients of the $\mathrm{CH}_{3} \mathrm{I}-\mathrm{O}_{2}$ and $\mathrm{CH}_{3} \mathrm{I}-\mathrm{N}_{2}$ [Attafi et al., J Quant Spectrosc Radiat Transf 231 (2019) 1-8] systems, we have produced the $\mathrm{CH}_{3} \mathrm{I}$-air broadening coefficients, ranging from 0.0783 to $0.1385 \mathrm{~cm}^{-1} \mathrm{~atm}^{-1}$ at $295 \mathrm{~K}$. The present results and the data already available should be valuable not only for predicting the $\mathrm{CH}_{3} \mathrm{I}$ infrared spectrum in the atmosphere, but also for verifying theoretical calculations of pressure-broadening and pressure-shift coefficients in the $v_{6}$ region of methyl iodide spectra.

Keywords: methyl iodide; $\mathrm{CH}_{3} \mathrm{I}$; high-resolution Fourier transform spectroscopy; $\mathbf{O}_{2}$ broadening and shift coefficients; $J$ and $K$ dependence 


\section{Introduction}

The modeling of gas-phase lineshapes is an important goal for the retrieval of observed earth and planet atmospheric spectra, as well as a test of molecular collision theories. The parameters required for this modeling are contained in databases such as HITRAN [1] and GEISA [2] and are continuously updated in terms of accuracy. Methyl iodide $\left(\mathrm{CH}_{3} \mathrm{I}\right)$ is emitted in the atmosphere by marine algae and photolyzed with a lifetime of the order of a week. It is a source of I atoms involved in the ozone destruction cycles in the upper troposphere and in the lower stratosphere [3]. Methyl iodide is also of nuclear interest. Indeed, volatile radioactive iodine species such as $\mathrm{CH}_{3} \mathrm{I}$ and molecular iodine $\left(\mathrm{I}_{2}\right)$ can be emitted in case of severe nuclear accident and exhibit high radio-contamination at short term because of the ${ }^{131} \mathrm{I}$ isotope [4]. Despite its atmospheric importance, methyl iodide is essentially absent from common spectroscopic databases. To fill this gap, we undertook a series of studies including line positions, line intensities, and pressure-broadening coefficients in order to generate for the $v_{6}$ band of $\mathrm{CH}_{3} \mathrm{I}$ at $11.2 \mu \mathrm{m}$ a line list which soon will be available in the GEISA database.

This molecule was the subject of numerous microwave and infrared studies focused on the ground and various excited states, and several combination bands (see [5,6 and references therein] for an exhaustive review on the spectroscopic parameters of $\mathrm{CH}_{3} \mathrm{I}$ ). To the best of our knowledge, only four studies dealt with the measurement of line broadening coefficients. Self-broadening parameters of 6 hyperfine components of the $(J=10 \rightarrow 9, \mathrm{~K} l=9)$ rotational transitions in the $\mathrm{v}_{6}=1$ excited vibrational state were accurately measured using Doppler-free double-resonance spectroscopy [7] and room temperature self-, $\mathrm{N}_{2^{-}}$and $\mathrm{O}_{2}$-broadening coefficients were measured for over 100 lines in five $Q$-branches of the $v_{5}$ perpendicular band at $7 \mu \mathrm{m}$ using diode laser absorption spectroscopy [8]. More recently, Raddaoui et al. [9] used high resolution Fourier transform spectra and a multispectrum fitting procedure with Voigt profile to retrieve self-broadening coefficients for around 1200 transitions of the $v_{6}$ band between 854 and $963 \mathrm{~cm}^{-1}$.

In our previous contributions, we recorded and analyzed high-resolution spectra of the $v_{6}$ band located in the $11.2 \mu \mathrm{m}$ spectral region. These studies led to a complete line positions analysis [5], absolute line intensities [6] and self- and $\mathrm{N}_{2}$-broadening coefficients of $\mathrm{CH}_{3} \mathrm{I}$ [10]. In this paper, we report measured and calculated $\mathrm{O}_{2}$-broadening coefficients of $\mathrm{CH}_{3} \mathrm{I}$ in the $v_{6}$ band. The $\mathrm{O}_{2}$-broadening coefficients were retrieved from fourteen high resolution 
Fourier transform spectra recorded at a temperature of $295 \mathrm{~K}$. An empirical model was developed to reproduce within experimental accuracy the large set of measured broadening coefficients covering various $J$ and $K$ values. It also reports the corresponding air-broadening coefficients and the first pressure-induced shift coefficients due to oxygen for rovibrational transitions in the $v_{6}$ band.

Section 2 details the experimental setup and conditions used to record the spectra. The measurements of $\mathrm{O}_{2}$-broadening and shift coefficients are described in Section 3. The empirical model developed to calculate $\mathrm{O}_{2}$ collisional broadening parameters of $\mathrm{CH}_{3} \mathrm{I}$ and comparisons of the present measurements with literature data are described in Section 4. Conclusions and remarks are provided in Section 5.

\section{Experimental details}

Fourteen absorption spectra of methyl iodide diluted in oxygen have been recorded in the range from 500 to $1450 \mathrm{~cm}^{-1}$, using the high-resolution Bruker IFS125HR FTS located at the LISA facility in Créteil (France). The instrument was equipped with a silicon carbide Globar source, a $\mathrm{KBr} / \mathrm{Ge}$ beamsplitter and a liquid nitrogen cooled $\mathrm{HgCdTe}$ (MCT) detector. An optical filter with a bandpass of $500-1450 \mathrm{~cm}^{-1}$ was used to improve the signal-to-noise ratio. The FTS was continuously evacuated below $3 \times 10^{-4} \mathrm{hPa}$ by a turbomolecular pump to minimize absorption by atmospheric gases. The diameter of the entrance aperture of the spectrometer was set to $2 \mathrm{~mm}$ to maximize the intensity of infrared radiation falling onto the MCT detector without saturation or loss of spectral resolution. Interferograms were recorded with a $40 \mathrm{kHz}$ scanner frequency and a maximum optical path difference (MOPD) of $150 \mathrm{~cm}$. According to the Bruker definition (resolution $=0.9 / \mathrm{MOPD}$ ), this corresponds to a resolution of $0.006 \mathrm{~cm}^{-1}$.

The $\mathrm{O}_{2}$ and $\mathrm{CH}_{3} \mathrm{I}$ samples were purchased from Sigma Aldrich with stated purities of $99.99 \%$ and $99 \%$, respectively. No further sample purifications were done. The absorption cell has a base path length of $20 \mathrm{~cm}$ and was adjusted for 28 transits in the present experiment, yielding an absorption path length of $564.9 \pm 1.1 \mathrm{~cm}$. The path length includes the distance between the surface of the field mirror and the windows of the cell $(2 \times 2.45 \mathrm{~cm})$. The spectra were recorded at a stabilized room temperature of $295 \pm 1 \mathrm{~K}$. The sample pressure in the cell was measured using calibrated MKS Baratron capacitance manometers models 628D (2 and 10 Torr full scale) and 627D (100 and 1000 Torr full scale), characterized by a stated reading accuracy of $0.12 \%$. Considering the uncertainty arising from small variations of the pressure 
during the recording of the interferograms ( 0.35\%), we estimated the measurement uncertainty on the pressure to be equal to $0.5 \%$.

The following procedure was used for the measurements. A background spectrum was first recorded at a resolution of $0.01 \mathrm{~cm}^{-1}$ while the cell was being continuously evacuated. The cell was then filled with $\mathrm{CH}_{3} \mathrm{I}$ at a given pressure, followed by the perturbing gas leading to a series of 14 total pressures. One $\mathrm{CH}_{3} \mathrm{I} / \mathrm{O}_{2}$ spectrum was recorded for each $\mathrm{CH}_{3} \mathrm{I}$ filling. Transmittance spectra were finally generated from the ratio of the sample spectra with the background spectrum. The fourteen pressures chosen and the number of interferograms recorded and averaged to yield the corresponding spectra are listed in Table 1. For the Fourier transform, a Mertz-phase correction with a $1 \mathrm{~cm}^{-1}$ phase resolution, a zero-filling factor of 2 and no apodization (boxcar option) were applied to the averaged interferograms. The root mean square (RMS) S/N in the ratioed spectra is around 300. The spectra were calibrated by matching the measured positions of about 30 lines of residual $\mathrm{CO}_{2}$ observed therein to reference wavenumbers available in HITRAN [1] with a RMS deviation of $0.00028 \mathrm{~cm}^{-1}$.

\section{Retrieval of the broadening and shift coefficients and uncertainty analysis}

\subsection{Retrieval of oxygen-broadening and shift coefficients}

The $\mathrm{CH}_{3} \mathrm{I} / \mathrm{O}_{2}$ collisional half widths and pressure-induced shifts were measured using a mono-spectrum non-linear least squares fitting program, already used and described in previous works [11-16]. Briefly, the measurements involved the adjustment of a calculated spectrum to the observed spectrum, using a non-linear least squares fitting procedure. Each calculated spectrum was computed as the convolution of a Voigt-type transmission spectrum with an instrument line shape function, which included the effects of the finite maximum optical path difference and of the finite source aperture diameter of the interferometer [17]. In the present work, no deviation from this instrument line shape model was observed using the nominal aperture diameter of $2 \mathrm{~mm}$. The background in each spectrum was represented by a polynomial expansion up to the second order (a constant or an affine function was however found sufficient in most cases) and the profile of the lines was modeled using a Voigt function with Gaussian width always held fixed to the value calculated for the Doppler broadening. Line mixing effects were found to be negligible at these pressures. The measurements were carried out on small spectral intervals, ranging from 0.1 to $0.5 \mathrm{~cm}^{-1}$ and containing one to 
several lines. An example of the fitting procedure is shown in Fig. 1. The absence of signatures out of the spectral noise in the residuals suggests that the Voigt profile is adequate to fit the observed lines.

\subsubsection{Oxygen broadening coefficients}

Although the spectra of the $\mathrm{CH}_{3} \mathrm{I} / \mathrm{O}_{2}$ mixtures have been recorded with at most $1.3 \%$ of $\mathrm{CH}_{3} \mathrm{I}$, we subtracted the self-broadening contributions to deduce at best $\mathrm{O}_{2}$-broadening coefficients, according to the equation:

$$
\gamma_{\mathrm{C}}=\gamma_{\mathrm{O}_{2}} \times \mathrm{P}_{\mathrm{O}_{2}}=\gamma_{\mathrm{C}, \text { total }}-\gamma_{\text {self }} \times \mathrm{P}_{\mathrm{CH}_{3} \mathrm{I}}
$$

where $\gamma_{c}$ is the $\mathrm{O}_{2}$-collisional halfwidth, $\gamma_{c, \text { total }}$ is the total collisional halfwidth, and $P_{C H_{3} I}$ and $P_{O_{2}}$ are the $\mathrm{CH}_{3} \mathrm{I}$ and $\mathrm{O}_{2}$ partial pressures, respectively. $\gamma_{O_{2}}$ is the $\mathrm{O}_{2}$-broadening coefficient and $\gamma_{\text {self }}$ is the self-broadening coefficient. The self-broadening coefficients used are those given in Ref. [10]. The evolution with the $\mathrm{O}_{2}$ pressure of the $\mathrm{O}_{2}$-collisional halfwidth $\gamma_{c}$ measured for the ${ }^{R} R\left(16,3, \mathrm{~A}_{1}\right),{ }^{P} R\left(16,3, \mathrm{~A}_{1}\right)$ and ${ }^{R} R\left(37,0, \mathrm{~A}_{2}\right)$ lines of the $v_{6}$ band of $\mathrm{CH}_{3} \mathrm{I}$ is shown in Fig. 2. The fitted straight lines show the linear dependence of the collisional halfwidths with pressure. The $\mathrm{O}_{2}$-broadening coefficients (in $\mathrm{cm}^{-1} \mathrm{~atm}^{-1}$ ) can be derived from the slopes of these lines. In our analysis, we did not apply any temperature corrections to the measured $\mathrm{O}_{2}$-broadening coefficients. Hence, the $\mathrm{O}_{2}$-broadening coefficients listed in the supplementary material correspond to the temperature of $295 \pm 1 \mathrm{~K}$ at which the spectra were recorded. The measured $\mathrm{O}_{2}$-broadening coefficients range from 0.0648 to $0.1207 \mathrm{~cm}^{-1} \mathrm{~atm}^{-1}$ at 295 K. A few transitions are collected in Table 2, together with their absolute uncertainty.

\subsubsection{Oxygen pressure-induced shift coefficients}

The pressure-induced shift coefficients $\delta^{0}\left(\mathrm{~cm}^{-1} \mathrm{~atm}^{-1}\right.$ at the temperature of the spectra) were determined using the following expression:

$$
\sigma=\sigma_{0}+\delta^{0} \times \mathrm{P}_{\mathrm{O}_{2}}
$$

where $\sigma_{0}\left(\mathrm{~cm}^{-1}\right)$ is the unperturbed wavenumber and $\sigma\left(\mathrm{cm}^{-1}\right)$ the line position corresponding to a given total pressure. Typical plot of the collisional wavenumber $\sigma$ as a function of the pressure $P_{O_{2}}$ is shown in Fig. 3. The straight line obtained from the fitting illustrates the linearity of the measured wavenumber against pressure. The $\mathrm{O}_{2}$-shift coefficients $\delta^{0}$ can be derived from the slope of this straight line. To our knowledge, the oxygen-induced pressure 
shift coefficients reported in this study are the only measured shift coefficients available for $\mathrm{CH}_{3}$ I. The $\mathrm{O}_{2}$ pressure-induced shift coefficients, $\delta^{0}$ in $\mathrm{cm}^{-1} \mathrm{~atm}^{-1}$, determined for the $v_{6}$ lines of $\mathrm{CH}_{3} \mathrm{I}$ are listed in the supplementary material and a few transitions are collected in Table 2, together with their absolute uncertainty. All measured oxygen pressure-induced shifts for $\mathrm{CH}_{3} \mathrm{I}$ lines in the $v_{6}$ band are negative (see Figure 4) and varied between -0.00044 and $-0.04984 \mathrm{~cm}^{-1} \mathrm{~atm}^{-1}$. The shift coefficients did not clearly displayed a distinguishable $J$ dependence.

\subsection{Uncertainty analysis}

Examination of the percent differences between the observed and best-fit calculated spectra (for example shown in the lower panel of Fig. 1) shows that they are generally less than $1 \%$. However, estimation the accuracy of the measured broadening coefficients requires considering the uncertainties on all physical parameters, contributions from possible systematic errors $[18,19]$ together with the standard deviation of the fits. These various sources of error and their associated uncertainties expressed relative to the broadening coefficients are given in Fig. 5 for 3 selected lines, representative of the 263 measured lines, i.e. ${ }^{R} R(16,3),{ }^{P} R(16,3)$ and ${ }^{R} R(37,0)$. Figure 5 shows that systematic errors are likely to dominate the measurement uncertainty. The dominant contributions to systematic errors arise from the location of the full-scale photometric level, channeling, as well as electronic and detector nonlinearities $[18,19]$. A realistic assessment of systematic photometric errors is not an easy task and probably strongly depends on the setup used. We base our present estimate on the arguments developed in Ref. [19] using instruments comparable to ours. In particular, $\mathrm{HgCdTe}$ detectors are used for their high sensitivity, but are also known for their deviation to a linear behavior. When using an $\mathrm{HgCdTe}$ for mid-infrared measurements, deviations up to $2.3 \%$ on retrieved parameters were found when compared to that derived using more linear detectors such as InSb or DTGS ones. We therefore retained a 3\% value for the contribution of systematic errors. For each transition, we then estimated the accuracy of the measured $\mathrm{O}_{2^{-}}$ broadening and shift coefficients from the uncertainties on the individual experimental parameters, i.e. $\varepsilon_{\mathrm{si}}$ (sample purity), $\varepsilon_{\mathrm{t}}$ (temperature), $\varepsilon_{\mathrm{p}}$ (pressure), $\varepsilon_{\mathrm{pl}}$ (pathlength), $\varepsilon_{\mathrm{fit}}$ (standard deviation from fit) and $\varepsilon_{\mathrm{sys}}$ (systematic errors), assuming that these uncertainties are uncorrelated:

$$
\varepsilon=\sqrt{\varepsilon_{s i}^{2}+\varepsilon_{t}^{2}+\varepsilon_{p}^{2}+\varepsilon_{p l}^{2}+\varepsilon_{f i t}^{2}+\varepsilon_{s y s}^{2}}
$$


Considering these various sources of errors we estimate that, on average, the errors in the $\mathrm{O}_{2^{-}}$ broadening coefficients and pressure shift coefficients is about $4 \%$ and $11 \%$, respectively.

\section{Calculated $\mathrm{O}_{2}$ and air collisional broadening parameters and discussion}

\subsection{Empirical model}

We have fitted the measured $\mathrm{O}_{2}$-broadening coefficients to an empirical polynomial expression as previously done for the self- and $\mathrm{N}_{2}$-broadening coefficients of $\mathrm{CH}_{3} \mathrm{I}[9,10]$. Such a work requires a great amount of accurate measurements. Each set of broadening coefficients, characterized by the same $J$ value, was fitted to the following polynomial expansion :

$$
\gamma_{J}(K)=a_{J}^{0}+a_{J}^{2} K^{2}
$$

Examples of these fits are given in Fig. 6 for transitions with $J=8,11,32$ and 46. As has been observed in numerous studies dealing with $\mathrm{C}_{3 \mathrm{v}}$-symmetry molecules [20-24], the broadening coefficients decrease with $K$. This decrease is more significant at low $J$ than at high $J$ values. The best-fit coefficients $a_{J}^{0}$ and $a_{J}^{2}$ were determined through a least-squares fit of the experimental broadening coefficients. They are listed in Table 3. The calculated $\mathrm{O}_{2-}$ broadening coefficients $\left(\gamma_{\text {calc }}\right)$ corresponding to the measured values $\left(\gamma_{\text {mea }}\right)$ are presented in Table 2, together with the differences between the measured and calculated values. A statistical analysis of these differences (Table 4) shows that the fit is very good because at least $95 \%$ of the broadening coefficients fall within $6 \%$ of the measured values. On average, the empirical expression reproduces the measured $\mathrm{O}_{2}$-broadening coefficients to within $3 \%$. The latter range corresponds to the measurement uncertainty of the broadening coefficients. Figure 7 is a plot of the $J$-dependence of the $\mathrm{O}_{2}$-broadening coefficients, measured and calculated for all studied $\mathrm{K}$ values in the $v_{6}$ band of $\mathrm{CH}_{3} \mathrm{I}$. Figure 7 shows that the $\mathrm{O}_{2}$ broadening coefficients decrease with increasing $J$. The use of these empirical models to determine the broadening coefficients far outside the quantum number range of the present measurements may not yield reliable values and therefore should be avoided. We will here thus limit the prediction to the quantum number range $0 \leq K \leq 7$ and $0 \leq J \leq 51$. Figure 8 shows an example of these predictions for $K=0$ and 1 .

\subsection{Air-broadening coefficients}

The values for nitrogen [10] and oxygen-broadening given in Table 2 and in the supplementary material can be introduced into the equation: 


$$
\gamma_{\text {air }}=0.79 \times \gamma_{\mathrm{N}_{2}}+0.21 \times \gamma_{\mathrm{O}_{2}}
$$

in order to produce air-pressure broadening coefficients. The values of the air-broadening coefficients derived from the measured nitrogen- and oxygen-broadening coefficients ranges from 0.0783 to $0.1385 \mathrm{~cm}^{-1} \mathrm{~atm}^{-1}$ at $295 \mathrm{~K}$. Few transitions of the air-broadening coefficients are listed in column (i) of Table 2. The whole set of these coefficients is presented in the supplementary material. Figure 9 is a plot of the $J$-dependence of the air-broadening coefficients for $K=2$ and 4 . The calculated values are those derived from the empirical model and reproduce very well those derived from the measurements.

\subsection{Comparison with previous work}

Figure 10 compares the present results of $\mathrm{O}_{2}$-broadening coefficients for the ${ }^{P} Q(J, 4)$ transitions in the $v_{6}$ band and the measurements reported in Ref. [8] for the same transitions in the $v_{5}$ band. The present $\mathrm{O}_{2}$-broadening coefficients are a little larger than those of the $v_{5}$ band but are of comparable magnitude, with average differences of about $8 \%$. This comparison tends to indicate the absence of a marked vibrational dependence of the $\mathrm{O}_{2}$-broadening coefficients.

The present $\mathrm{O}_{2}$-shift coefficients for the ${ }^{P} P(J, 4)$ transitions are compared with measurements reported in Ref. [25] for the same transitions in the $v_{6}$ band of $\mathrm{CH}_{3} \mathrm{~F}-\mathrm{Ar}$ system and shows the same order of magnitude and trend, see Figure 11.

\section{Conclusion}

The present study reports the first extensive experimental determination of $\mathrm{O}_{2}$ pressure-broadening and pressure-shift coefficients of the $\mathrm{CH}_{3} \mathrm{I} v_{6}$ band. The results were obtained by analyzing fourteen high-resolution room temperature laboratory absorption spectra of methyl iodide diluted in oxygen at total pressures in the range $20-295 \mathrm{hPa}$ with a mono-spectrum non-linear least squares fitting of Voigt profiles. $\mathrm{O}_{2}$-broadening coefficients have been obtained for large sets of $J$ and $K$ values, for which clear $J$ and $K$ dependences have been observed. The $\mathrm{O}_{2}$-broadening coefficients results obtained in the present work are of comparable magnitudes with the values reported in the literature for the $v_{5}$ band of $\mathrm{CH}_{3} \mathrm{I}$, with average differences of about $8 \%$. Empirical polynomial expression have been used to model the rotational $K$ dependence of the $\mathrm{O}_{2}$-broadening coefficients, leading to accurate coefficients $\left(a_{J}^{0}\right.$ and $a_{J}^{2}$ ) for methyl iodide. Using the measured broadening coefficients of the $\mathrm{CH}_{3} \mathrm{I}-\mathrm{O}_{2}$ 
and $\mathrm{CH}_{3} \mathrm{I}-\mathrm{N}_{2}$ systems, we have produced the $\mathrm{CH}_{3} \mathrm{I}$-air broadening coefficients. For the first time, oxygen pressure-induced shifts for $\mathrm{CH}_{3} \mathrm{I}$ lines were measured and did not clearly displayed a distinguishable $J$ dependence. Our previous contributions of the $\mathrm{CH}_{3} \mathrm{I} v_{6}$ band led to a complete line positions analysis [5], absolute line intensities [6] and self- and $\mathrm{N}_{2^{-}}$ broadening coefficients of $\mathrm{CH}_{3} \mathrm{I}$ [10]. Using all these and the present results, we will generate a line list for the $v_{6}$ band of $\mathrm{CH}_{3} \mathrm{I}$ at $11.2 \mu \mathrm{m}$, which soon will be available in the GEISA database.

\section{$\underline{\text { ACKNOWLEDGEMENTS }}$}

This study is supported by the DECA-PF project, sponsored by the French government 'Investments for the future' program through the grant ANR-11-RSNR-0003 supervised by the French National Research Agency (ANR) under the 'Research in Nuclear Safety and Radioprotection' (RSNR) research initiative. 


\section{$\underline{\text { References }}$}

[1] Gordon IE, Rothman LS, Hill C, Kochanov RV, Tana Y, Bernath PF, BirkM, Boudon V, Campargue A, Chance KV, Drouin BJ, Flaud JM, Gamache RR, Hodges JT, Jacquemart D, Perevalov VI, Perrin A, Shine KP, Smith MA, Tennyson J, Toon GC, Tran H, Tyuterev VG, Barbe A, Császár AG, Devi VM, Furtenbacher T, Harrison JJ, Hartmann JM, Jolly A, Johnson TJ, Karman T, Kleiner I, Kyuberis AA, Loos J, Lyulin OM, Massie ST, Mikhailenko SN, Moazzen-Ahmadi N, Müller HSP, Naumenko OV, Nikitin AV, Polyansky OL, Rey M, Rotger M, Sharpe SW, Sung K, Starikova E, Tashkun SA, Vander Auwera J, Wagner G, Wilzewski J, Wcisło P, Yuh S, Zak EJ. The HITRAN 2016 molecular spectroscopic database. J Quant Spectrosc Radiat Transf 2017;203:3-69.

[2] Jacquinet-Husson N, Armante R, Scott NA, Chédin A, Crépeau L, Boutammine C, Bouhdaoui A, Crevoisier C, Capelle V, Boonne C, Poulet-Crovisier N, Barbe A, Benner DC, Boudon V, Brown LR, Buldyreva J, Campargue A, Coudert LH, Devi VM, Down MJ, Drouin BJ, Fayt A, Fittschen C, Flaud JM, Gamache RR, Harrison JJ, Hill C, Hodnebrog Ø, Hu SM, Jacquemart D, Jolly A, Jiménez E, Lavrentieva N, Liu AW, Lodi L, Lyulin OM, Massie ST, Mikhailenko S, Müller HSP, Naumenko OV, Nikitin A, Nielsen CJ, Orphal J, Perevalov V, Perrin A, Polovtseva E, Predoi-Cross A, Rotger M, Ruth AA, Shanshan Y, Sung K, Tashkun S, Tennyson J, Tyuterev VG, Vander Auwera J, Voronin B, Makie A. The 2009 edition of the GEISA spectroscopic database. J Mol Spectrosc 2016;327:31-72.

[3] Bell N, Hsu L, Jacob DJ, Schultz MG, Blake DR, Butler JH, King DB, Lobert JM, Maier-Reimer E. Methyl iodide: Atmospheric budget and use as a tracer of marine convection in global models. J Geophys Res 2002;107(D17):4340.

[4] Clément B, Cantrel L, Ducros G, Funke F, Herranz L, Rydl A, Weber G, Wren C. State of the art report on iodine chemistry. OECD/CSNI Report NEA/CSNI/R 1; 2007.

[5] Perrin A, Haykal I, Kwabia-Tchana F, Manceron L, Doizi D, Ducros G. New analysis of the $v_{6}$ and $2 v_{3}$ bands of methyl iodide $\left(\mathrm{CH}_{3} \mathrm{I}\right)$. J Mol Spectrosc 2016;324:28-35. 
[6] Kwabia Tchana F, Attafi Y, Manceron L, Doizi D, Vander Auwera J, Perrin A. Line intensities for the $v_{6}$ and $2 v_{3}$ bands of methyl iodide $\left({ }^{12} \mathrm{CH}_{3} \mathrm{I}\right)$. J Quant Spectrosc Radiat Transf 2019;222-223:130-7.

[7] Belli S, Buffa G, Di Lieto A, Minguzzi P, Tarrini O, Tonelli M. Hyperfine level dependence of the pressure broadening of $\mathrm{CH}_{3} \mathrm{I}$ rotational transitions in the $\mathrm{v}_{6}=1$ vibrational state. J Mol Spectrosc 2000;201:314-18.

[8] Hoffman KJ, Davies PB. Pressure broadening coefficients of $v_{5}$ fundamental band lines of $\mathrm{CH}_{3} \mathrm{I}$ at $7 \mu \mathrm{m}$ measured by diode laser absorption spectroscopy. J Mol Spectrosc 2008;252:101-07.

[9] Raddaoui E, Troitsyna L, Dudaryonok A, Soulard P, Guinet M, Aroui H, Buldyreva J, Lavrentieva N, Jacquemart D. Line parameters measurements and modeling for the $v_{6}$ band of $\mathrm{CH}_{3} \mathrm{I}$ : A complete line list for atmospheric databases. J Quant Spectrosc Radiat Transf 2019;232:165-179.

[10] Attafi Y, Ben Hassen B, Aroui H, Kwabia Tchana F, Manceron L, Doizi D, Vander Auwera J, Perrin A. Self and $\mathrm{N}_{2}$ collisional broadening of rovibrational lines in the $v_{6}$ band of methyl iodide $\left({ }^{12} \mathrm{CH}_{3} \mathrm{I}\right)$ at room temperature: The $\mathrm{J}$ and $\mathrm{K}$ dependence. $\mathrm{J}$ Quant Spectrosc Radiat Transf 2019;231:1-8.

[11] Kwabia Tchana F, Jacquemart D, Lacome N, Kleiner I, Orphal J. Absolute line intensities in methyl bromide: the 7- $\mathrm{mm}$ region. J Mol Spectrosc 2006;235:132-43.

[12] Kwabia Tchana F, Ngom M, Perrin A, Flaud JM, Lafferty WJ, Ndiaye SA, Ngom El A. Absolute line intensities for oxirane from 1420 to $1560 \mathrm{~cm}^{-1}$. J Mol Spectrosc 2013;292:1-4.

[13] Ngom M, Flaud JM, Kwabia Tchana F, Lafferty WJ, Landsheere X, Perrin A, Ngom El A. Absolute line intensities for the $v_{3}$ band of oxirane $\left(\mathrm{C}_{2} \mathrm{H}_{4} \mathrm{O}\right)$. Canadian Journal of Physics 2013;91(11):906-09.

[14] Kwabia Tchana F, Flaud JM, Lafferty WJ, Ngom. Absolute line intensities for oxirane in the $11.4 \mu \mathrm{m}$ spectral region. Mol Phys 2014;112:1633-38. 
[15] Boussetta Z, Kwabia Tchana F, Aroui H. Self- and $\mathrm{N}_{2}$-broadening of $\mathrm{CH}_{3} \mathrm{Br}$ rovibrational lines in the $v_{2}$ band: The $\mathrm{J}$ and $\mathrm{K}$ dependence. $\mathrm{J}$ Mol Spectrosc 2015;308/309:33-40.

[16] Ben Hassen A, Galalou S, Kwabia Tchana F, Dhib M, Aroui H. Self-and $\mathrm{N}_{2}$-collisional broadening coefficients of ethylene in the $1800-2350 \mathrm{~cm}^{-1}$ spectral region. J Mol Spectrosc 2016;326:73-80.

[17] Dana V, Mandin JY. New improvements in the determination of line parameters from FTS data. J Quant Spectrosc Radiat Transf 1992;48:725-31.

[18] Ballard J, Knight RJ, Vander Auwera J, Herman M, Di Lonardo G, Masciarelli G, Nicolaisen FM, Beukes JA, Christensen LK, McPheat R, Duxbury G, Freckleton R, Shine KP. An intercomparison of laboratory measurements of absorption cross-sections and integrated absorption intensities for HCFC-22. J Quant Spectrosc Radiat Transf 2000;66:109-28.

[19] Sharpe S, Johnson T, Sams R, Chu RP, Rhoderick G, Johnson P. Gas-phase databases for quantitative infrared spectroscopy. Appl Spectrosc 2004;58:1452-61.

[20] Jacquemart D, Kwabia Tchana F, Lacome N, Kleiner I. A complete set of line parameters for $\mathrm{CH}_{3} \mathrm{Br}$ in the 10- $\mu \mathrm{m}$ spectral region. J Quant Spectrosc Radiat Transf 2007;105:264302.

[21] Jacquemart D, Guinet M. Line parameters measurements and modeling for the $v_{6}$ band of $\mathrm{CH}_{3} \mathrm{~F}$ : generation of a complete line list for atmospheric databases. J Quant Spectrosc Radiat Transf 2016;185:58-69.

[22] Barbouchi Ramchani A, Jacquemart D, Dhib M, Aroui H. Line positions, intensities and self-broadening coefficients for the $v_{5}$ band of methyl chloride. J Quant Spectrosc Radiat Transf 2013;120:1-15.

[23] Bray C, Jacquemart D, Lacome N, Guinet M, Cuisset A, Eliet S, Hindle F, Mouret G, Rohart F, Buldyreva J. Self-broadening coefficients of methyl chloride transitions at room temperature. J Quant Spectrosc Radiat Transf 2013;116:88-100.

[24] Barbouchi Ramchani A, Jacquemart D. Line intensities and self-broadening coefficients for the $v_{2}$ band of methyl chloride. J Mol Spectrosc 2016;326:81-6. 
[25] Dhib D, Kwabia Tchana F, Landsheere X, Dhib M, Aroui H. Measurements and calculations of Ar-broadening and shifting parameters of $\mathrm{CH}_{3} \mathrm{~F}$ transitions in the $v_{6}$ band. J Quant Spectrosc Radiat Transf 2019;231:115-125.

\section{Figures}

\section{Figure 1}

The upper panel presents a small part of the spectrum of the $\mathrm{v}_{6}$ band of $\mathrm{CH}_{3}$ l perturbed by $\mathrm{O}_{2}$ (spectrum 1 in Table 1; open circles) overlaid by the corresponding best-fit calculated spectrum (solid line) obtained with a source aperture diameter of $2 \mathrm{~mm}$, a maximum optical path difference of 150 $\mathrm{cm}$ and a Voigt profile. The lower panel shows the percent differences between the observed and calculated spectra.
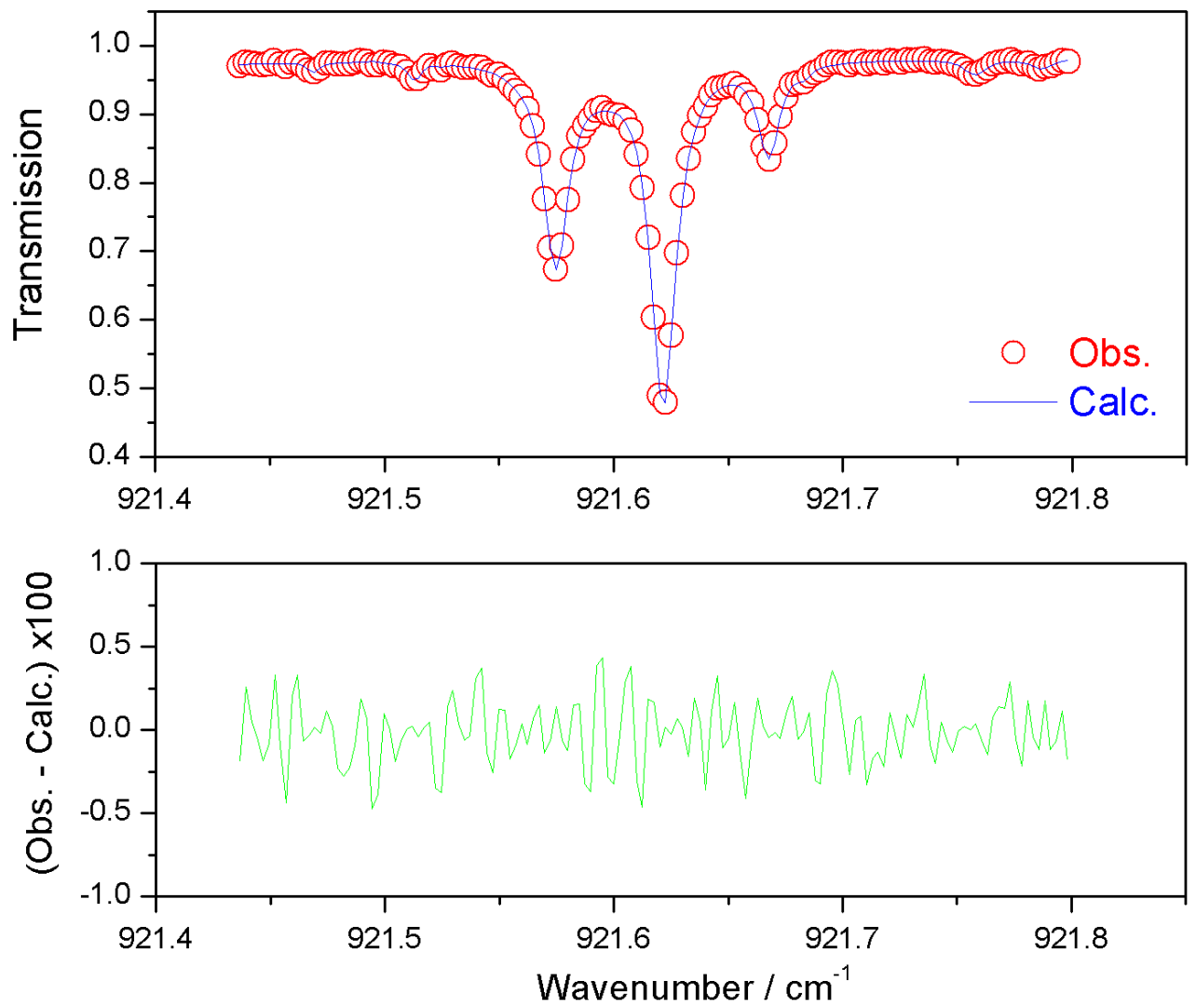


\section{Figure 2}

Evolution with pressure of the $O_{2}$-collisional halfwidths of the ${ }^{R} R\left(16,3, A_{1}\right),{ }^{P} R\left(16,3, A_{1}\right)$ and ${ }^{R} R\left(37,0, A_{2}\right)$ lines in the $\mathrm{v}_{6}$ band of $\mathrm{CH}_{3}$ l perturbed by $\mathrm{O}_{2}$. The slope of the best-fit lines represents the $\mathrm{O}_{2}$ broadening coefficients, $\gamma_{\mathrm{O}_{2}}$. The displayed error bars are twice the uncertainties of measurement.

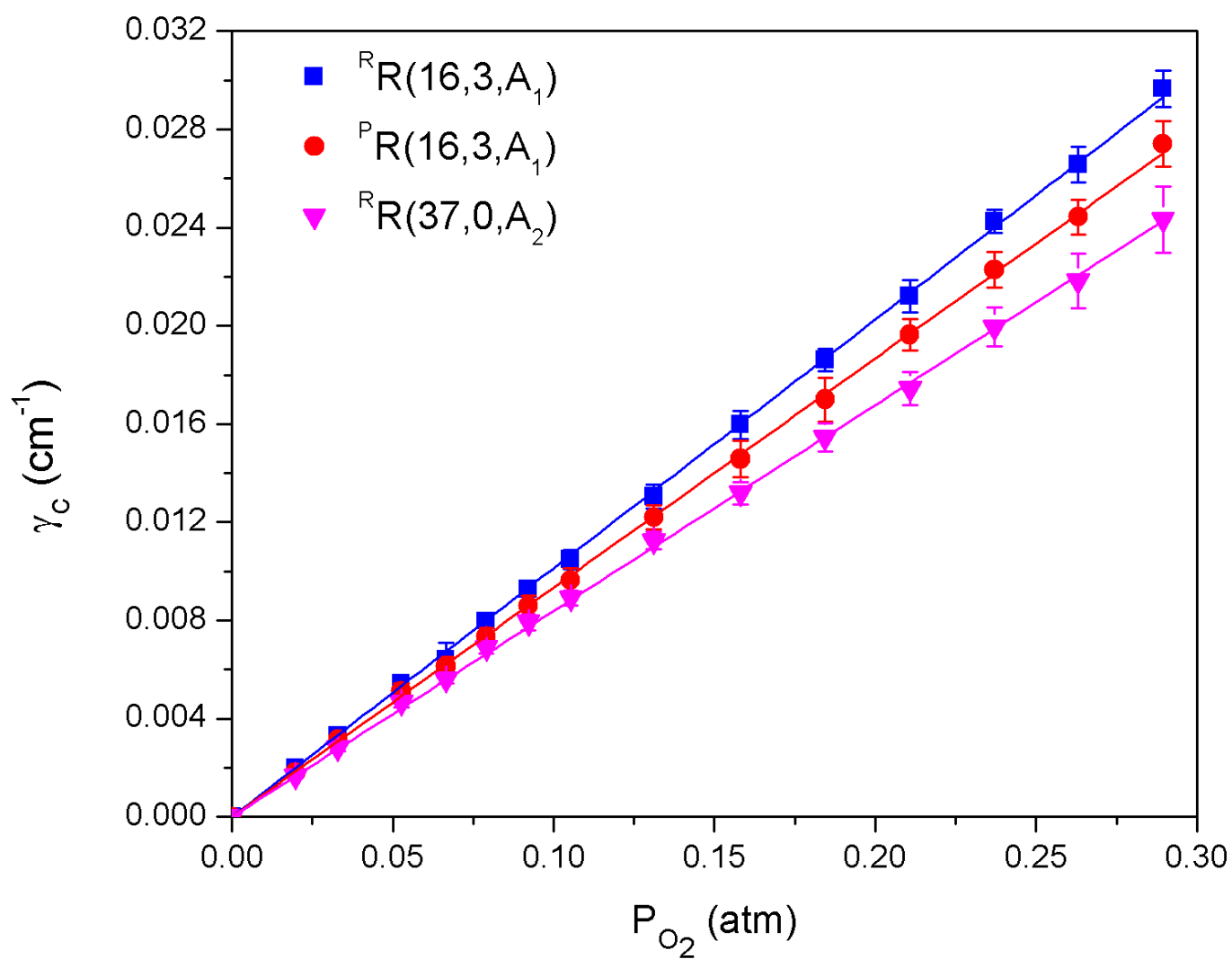




\section{Figure 3}

Dependence of measured wavenumber $\sigma$ with the oxygen partial pressure $P_{O_{2}}$ for the line ${ }^{R} R\left(9,6, A_{2}\right)$. The collisional line shift coefficient $\delta_{0}$ is the slope of the best fit line. $(\mathbf{\Delta})$ experimental data ; solid line : linear regression.

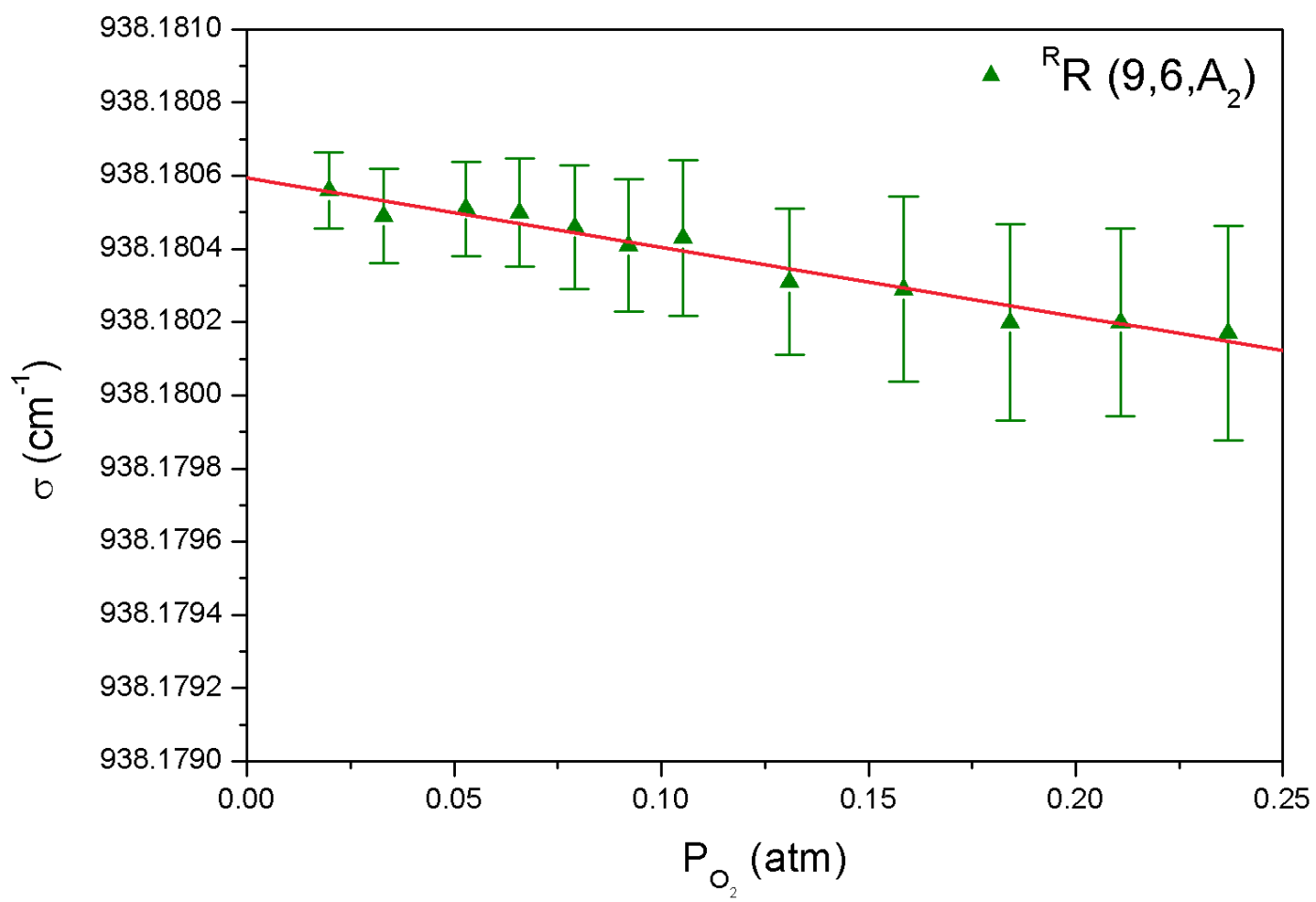




\section{Figure 4}

Measured $\mathrm{O}_{2}$-induced shift coefficients, $\delta^{0}$, in $\mathrm{cm}^{-1} \mathrm{~atm}^{-1}$ as a function of $J$ plotted for the $v_{6}$ band of $\mathrm{CH}_{3} \mathrm{I}$. Where error bars are not visible the uncertainties in the measured quantities are smaller than the size of the symbol used.

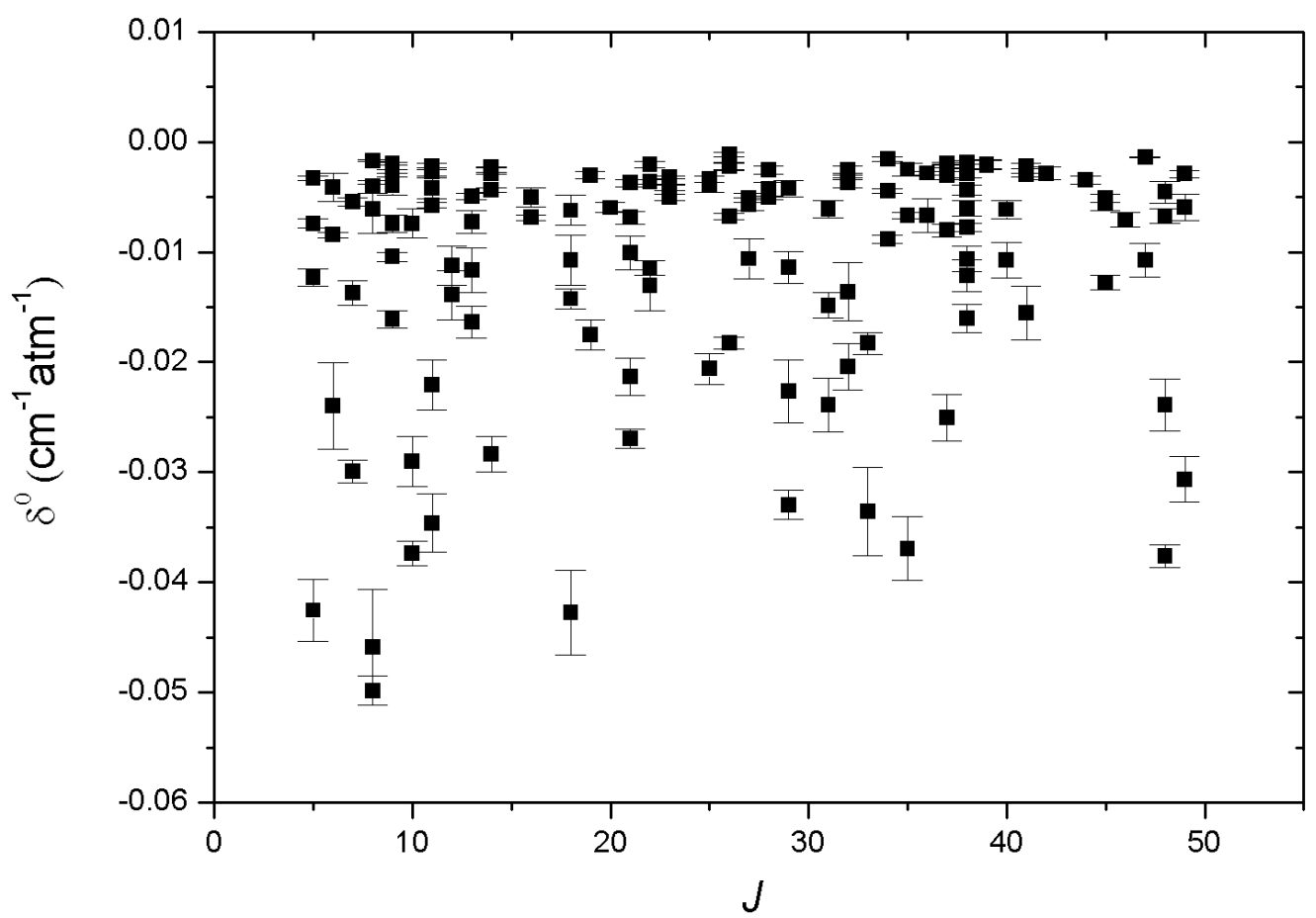




\section{Figure 5}

Comparison between various sources of relative uncertainty on the measured $\mathrm{O}_{2}$-broadening coefficients of 3 selected lines: ${ }^{R} R(16,3),{ }^{P} R(16,3)$ and ${ }^{R} R(37,0)$.

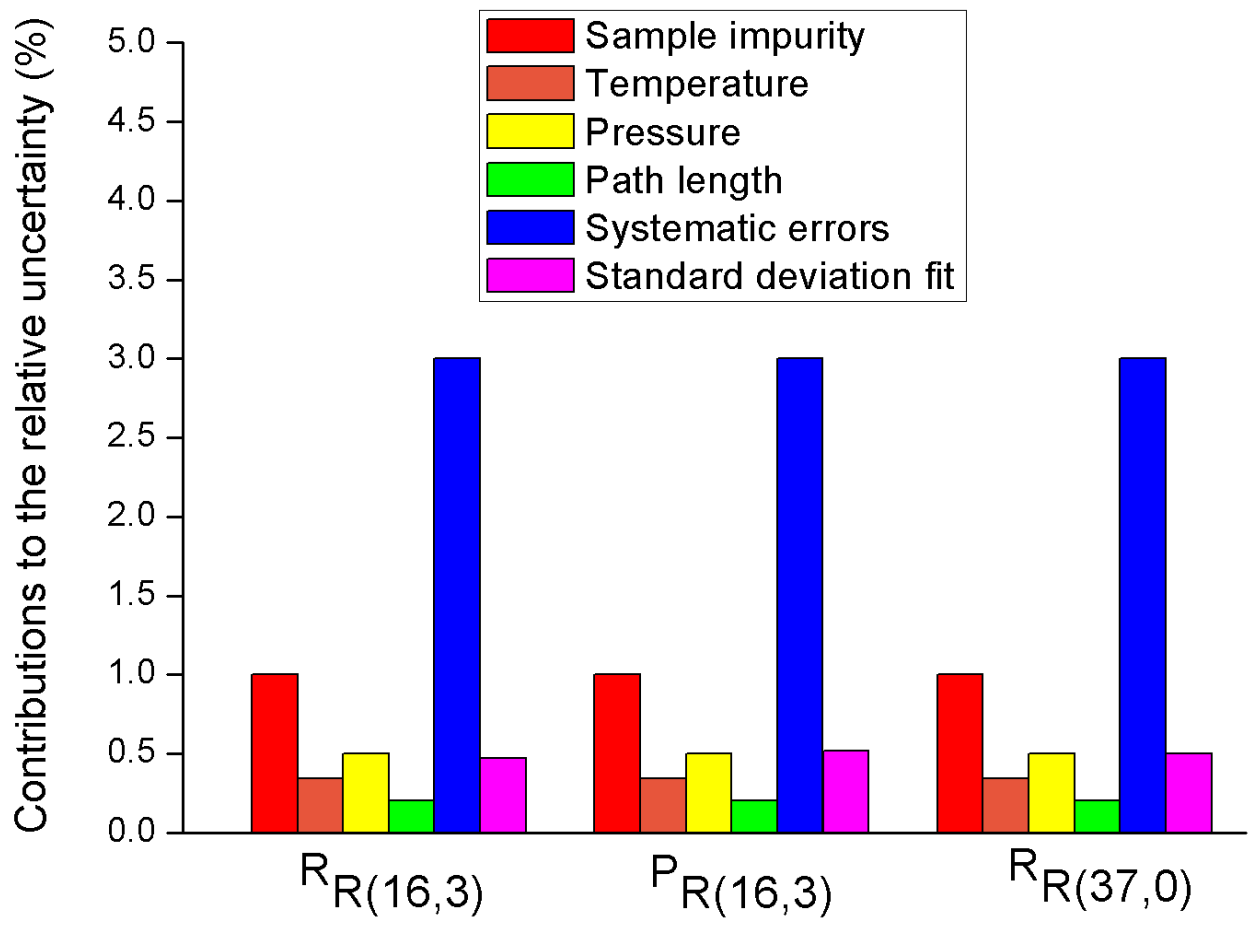




\section{Figure 6}

Examples of fits to Eq. (4) of the $\mathrm{O}_{2}$-broadening coefficients for sets of measurements corresponding to $J=8,11,32$ and 46 . The black up $(\boldsymbol{\Delta})$ and red down $(\nabla)$ triangles are the measured and corresponding calculated $\mathrm{O}_{2}$-broadening coefficients, respectively.
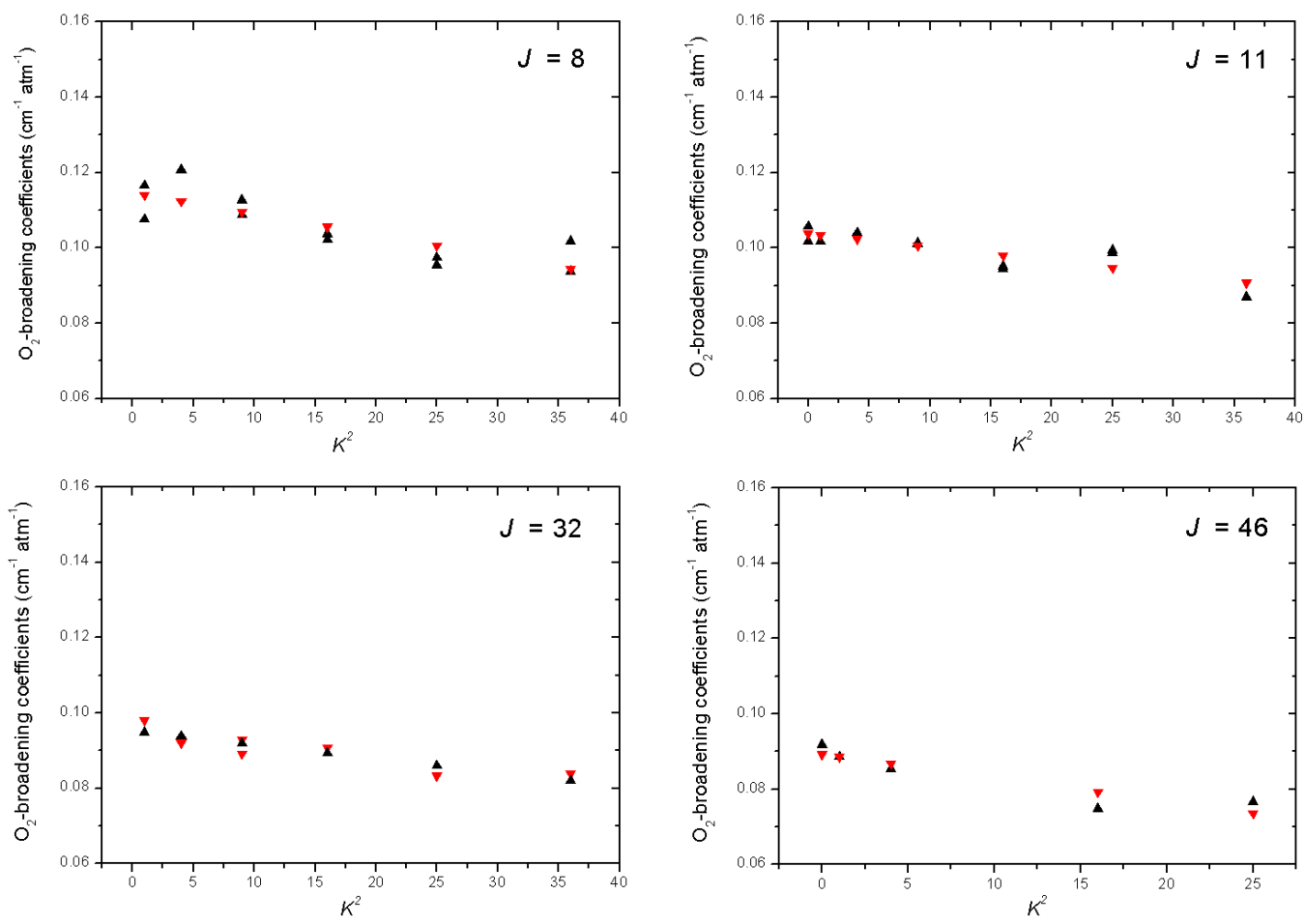
Figure 7

$J$-dependence of the measured and calculated $\mathrm{O}_{2}$-broadening coefficients for all studied $\mathrm{K}$ values in the $\mathrm{v}_{6}$ band of $\mathrm{CH}_{3} \mathrm{I}$.

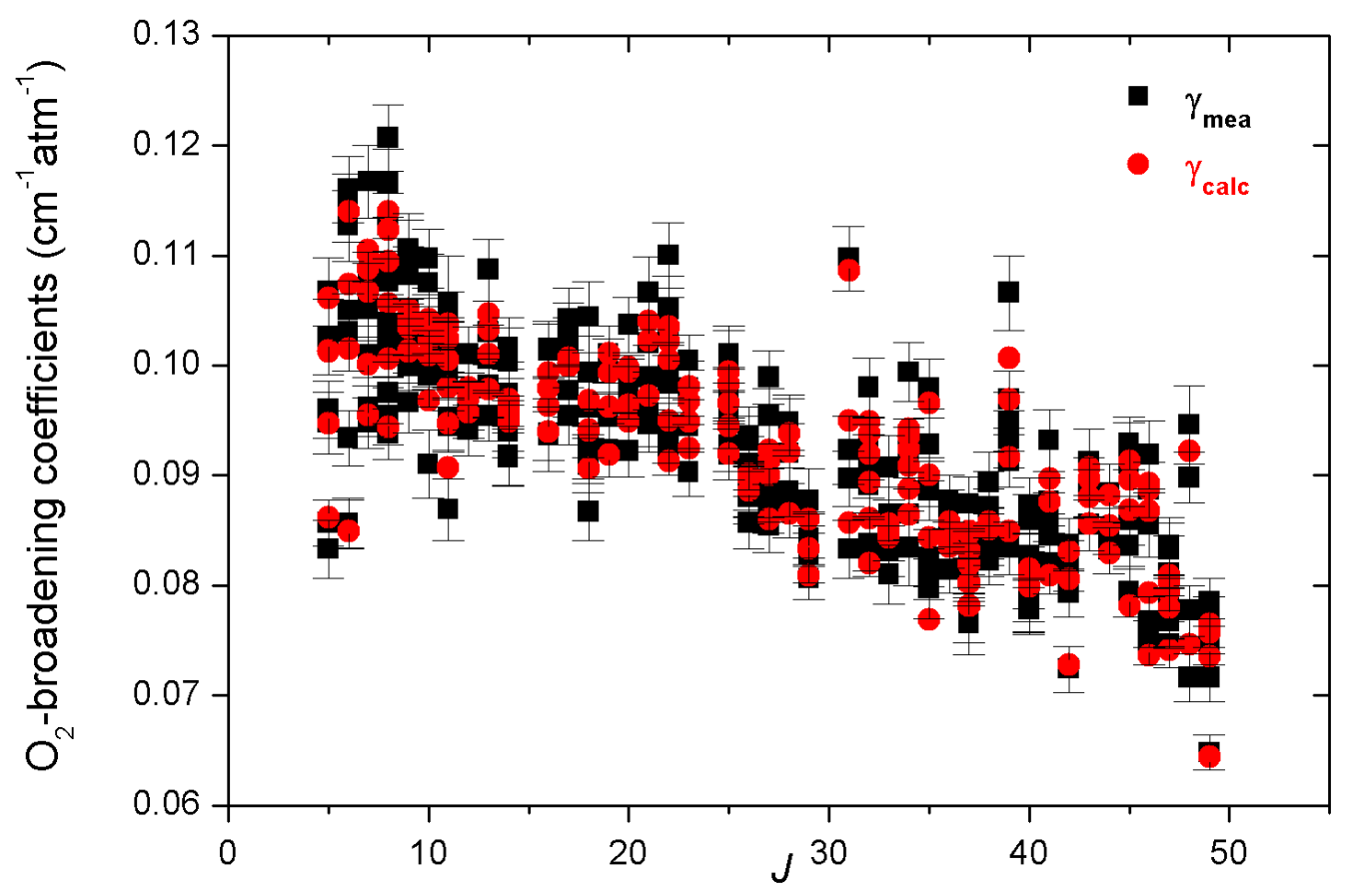




\section{Figure 8}

$J$-dependence of the measured and calculated $\mathrm{O}_{2}$-broadening coefficients for $K=0$ and 1 , in the $v_{6}$ band of $\mathrm{CH}_{3}$ I. The empirical model is used to predict unmeasured broadening coefficients.

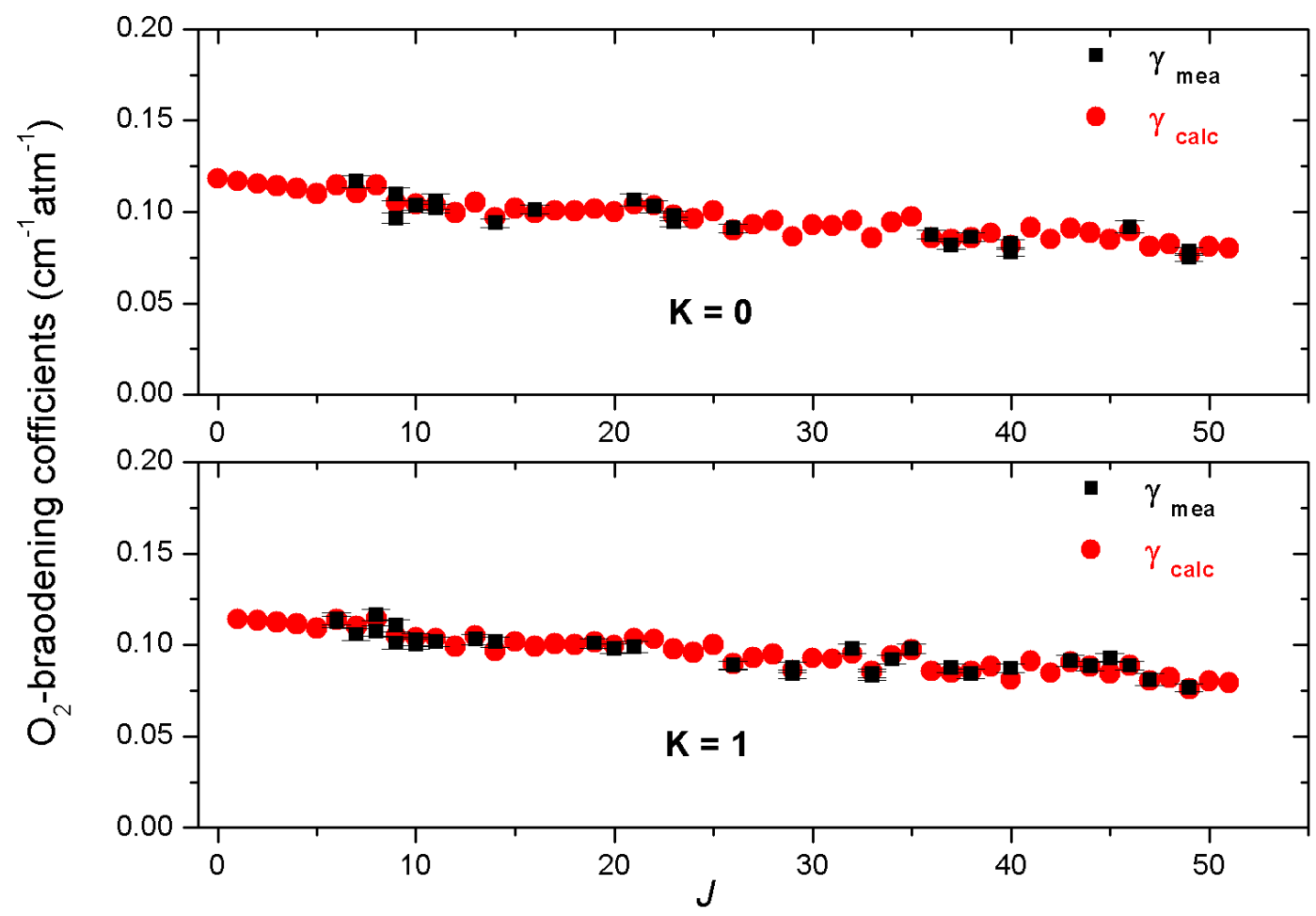

Figure 9

J-dependence of the air-broadening coefficients for $K=2$ and 4 , in the $\mathrm{v}_{6}$ band of $\mathrm{CH}_{3} \mathrm{I}$. The measured values are those derived from the measured nitrogen and oxygen broadening coefficients and the calculated ones from the empirical model, using Eq. (5). 


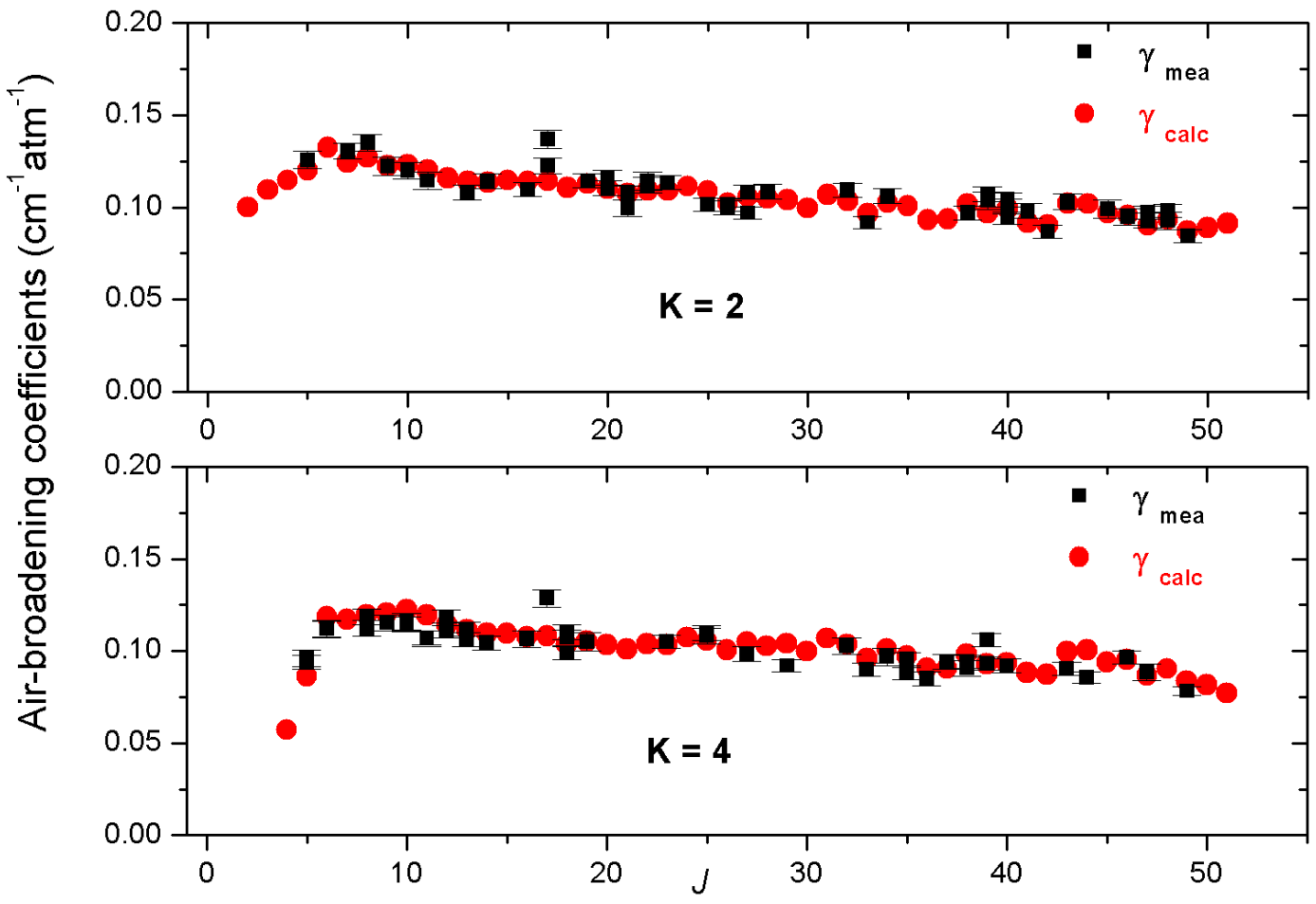


Figure 10

Comparison of room temperature $\mathrm{O}_{2}$-broadening coefficients measured in this work for ${ }^{P} Q(J, 4)$ transitions in the $\mathrm{v}_{6}$ band of $\mathrm{CH}_{3} \mathrm{I}$ with results obtained by Hoffman and Davies [8] for the $\mathrm{v}_{5}$ band.

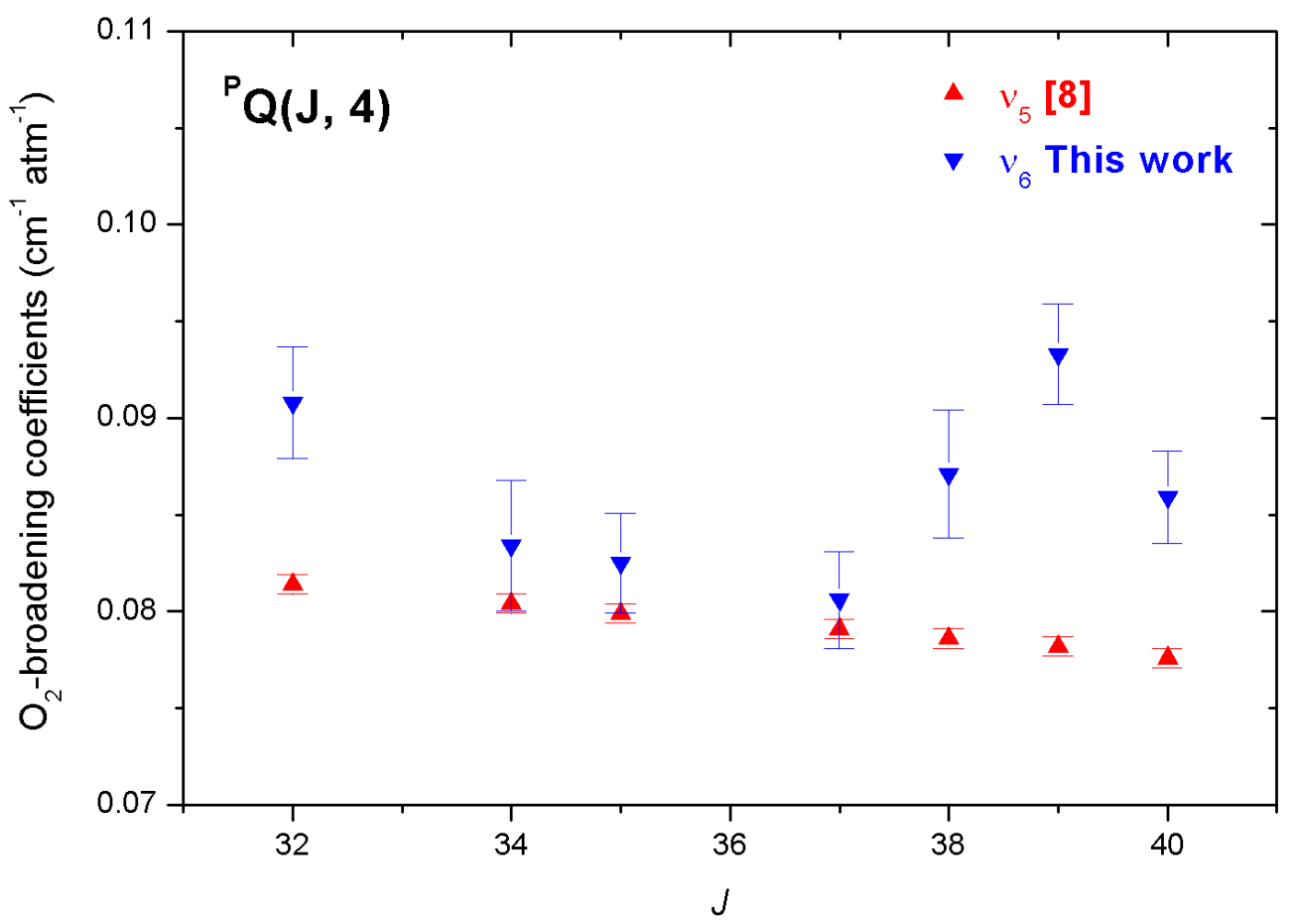


Figure 11

Comparison of the $\mathrm{O}_{2}$ shift coefficients measured in this work for ${ }^{P} P(J, 4)$ transitions in the $\mathrm{v}_{6}$ band of $\mathrm{CH}_{3} \mathrm{I}$ with results obtained by Dhib et al. [25] for the same transitions in the $\mathrm{v}_{6}$ band of $\mathrm{CH}_{3} \mathrm{~F}-\mathrm{Ar}$ system.

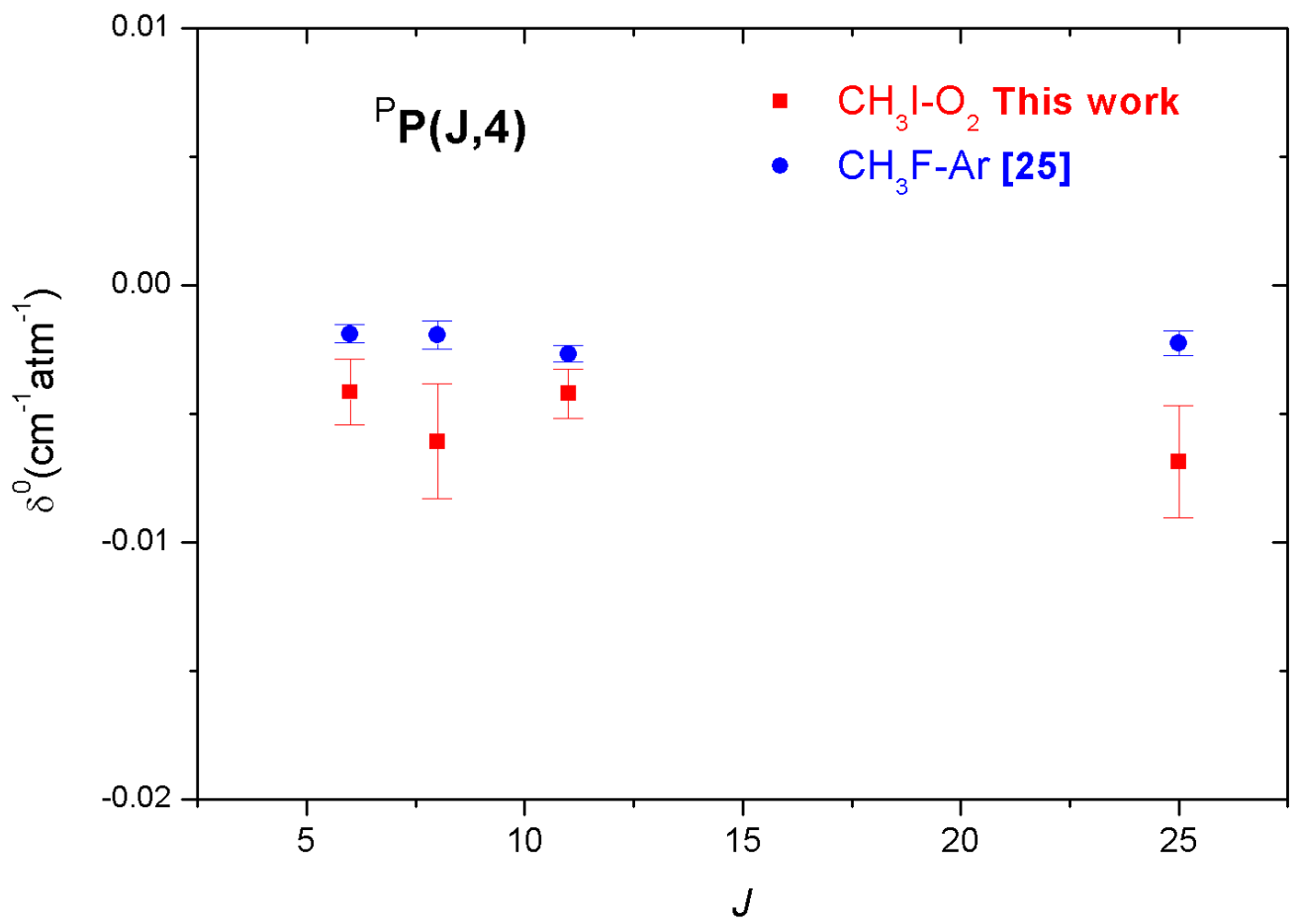


TABLE 1.

Pressures of $\mathrm{CH}_{3}$ l and $\mathrm{O}_{2}$ used to record the spectra. The numbers provided between parentheses are the uncertainties, estimated to be equal to $0.5 \%$ of the measured pressure.

\begin{tabular}{cccc}
$\#$ & $\mathrm{CH}_{3}$ I pressure $(\mathrm{hPa})$ & $\mathbf{O}_{2}$ pressure (hPa) & \# Scans \\
\hline S1 & $0.277(1)$ & $20.00(11)$ & 840 \\
S2 & $0.339(1)$ & $33.44(17)$ & 420 \\
S3 & $0.668(4)$ & $53.58(27)$ & 420 \\
S4 & $0.837(4)$ & $66.67(33)$ & 840 \\
S5 & $1.000(5)$ & $80.07(40)$ & 840 \\
S6 & $1.168(5)$ & $93.37(47)$ & 420 \\
S7 & $1.335(7)$ & $106.71(53)$ & 420 \\
S8 & $1.660(8)$ & $132.70(67)$ & 420 \\
S9 & $2.003(11)$ & $160.52(8)$ & 420 \\
S10 & $2.337(12)$ & $186.65(9)$ & 1020 \\
S11 & $2.668(13)$ & $213.6(1.1)$ & 420 \\
S12 & $3.001(15)$ & $240.0(1.2)$ & 840 \\
S13 & $3.345(17)$ & $266.6(1.3)$ & 420 \\
S14 & $3.665(19)$ & $292.0(1.3)$ & 840 \\
\hline
\end{tabular}


TABLE 2.

Broadening and shift coefficients of few transitions of the $v_{6}$ band of $\mathrm{CH}_{3} \mathrm{I}$. The whole set of measurements is provided as supplementary material.

\begin{tabular}{|c|c|c|c|c|c|c|c|c|c|c|c|c|c|c|}
\hline (a) & & (b) & & & (c) & & (d & & (e) & (f) & (g) & (h) & (i) & (j) \\
\hline 841.31415 & 26 & 3 & $\mathrm{E}$ & 27 & 4 & $\mathrm{E}$ & 3333 & \pm 0.0097 & $.1019 \pm 0.0034$ & $.0854 \pm 0.0024$ & 0.0900 & -5.4 & $0.0984 \pm 0.0042$ & $-0.01061 \pm 0.00181$ \\
\hline 842.19869 & 38 & -2 & A2 & 39 & 3 & $\mathrm{~A} 1$ & 0.2492 & \pm 0.0064 & $0.1042 \pm 0.0030$ & $0.0913 \pm 0.0024$ & 0.0969 & -6.1 & $0.1015 \pm 0.0038$ & $-0.00201 \pm 0.00042$ \\
\hline 346.61206 & 30 & -2 & A2 & 31 & 3 & $\mathrm{~A} 1$ & 0.3234 & \pm 0.0080 & $0.1165 \pm 0.0039$ & $0.1097 \pm 0.0029$ & 0.1086 & 1.0 & $0.1151 \pm 0.0049$ & $-0.01486 \pm 0.00115$ \\
\hline 354.19156 & 38 & 3 & $\mathrm{E}$ & 38 & 4 & $\mathrm{E}$ & 0.2350 & \pm 0.0060 & $0.0916 \pm 0.0027$ & $0.0871 \pm 0.0033$ & 0.0851 & 2.3 & $0.0907 \pm 0.0043$ & $-0.00606 \pm 0.00070$ \\
\hline 374.45867 & 6 & 0 & E & 7 & 1 & $\mathrm{E}$ & 0.2938 & \pm 0.0075 & $0.1254 \pm 0.0037$ & $0.1058 \pm 0.0035$ & 0.1101 & -4.1 & $0.1213 \pm 0.0051$ & $-0.02993 \pm 0.00102$ \\
\hline 378.31883 & 28 & 2 & E & 29 & 1 & $\mathrm{E}$ & 0.3280 & \pm 0.0087 & $0.1019 \pm 0.0026$ & $0.0841 \pm 0.0024$ & 0.0860 & -2.3 & $0.0982 \pm 0.0035$ & $-0.03296 \pm 0.00132$ \\
\hline 380.19430 & 37 & -2 & A2 & 36 & 3 & $\mathrm{~A} 1$ & 0.2703 & \pm 0.0068 & $0.0963 \pm 0.0023$ & $0.0837 \pm 0.0021$ & 0.0846 & -1.1 & $0.0937 \pm 0.0031$ & $-0.00671 \pm 0.00153$ \\
\hline 883.99619 & 49 & 1 & A1 & 49 & 0 & A2 & 0.1719 & \pm 0.0043 & $0.0881 \pm 0.0025$ & $0.0749 \pm 0.0021$ & 0.0765 & -2.1 & $0.0853 \pm 0.0033$ & $-0.00290 \pm 0.00032$ \\
\hline 388.88717 & 8 & 2 & $\mathrm{E}$ & 9 & 1 & $\mathrm{E}$ & 0.2967 & \pm 0.0076 & $0.1378 \pm 0.0035$ & $0.1106 \pm 0.0032$ & 050 & 5.1 & $0.1321 \pm 0.0047$ & $-0.00400 \pm 0.00082$ \\
\hline 890.89546 & 27 & 0 & $\mathrm{E}$ & 26 & 1 & $\mathrm{E}$ & 0.3455 & \pm 0.0088 & $0.1086 \pm 0.0026$ & $0.0887 \pm 0.0025$ & 0.0900 & -1.5 & $0.1044 \pm 0.0036$ & $-0.01827 \pm 0.00052$ \\
\hline 902.91549 & 37 & 1 & A2 & 36 & 0 & A1 & 0.2741 & \pm 0.0068 & $0.0950 \pm 0.0026$ & $0.0876 \pm 0.0024$ & 0.0858 & 2.1 & $0.0934 \pm 0.0035$ & $-0.00284 \pm 0.00014$ \\
\hline 904.24973 & 6 & -3 & $\mathrm{E}$ & 5 & -2 & $E$ & 0.2599 & \pm 0.0074 & $0.1308 \pm 0.0035$ & $0.1067 \pm 0.0031$ & 0.1061 & 0.6 & $0.1257 \pm 0.0047$ & $-0.00326 \pm 0.00020$ \\
\hline 906.67863 & 11 & -3 & $\mathrm{E}$ & 10 & -2 & E & 0.3351 & \pm 0.0084 & $0.1226 \pm 0.0036$ & $0.1097 \pm 0.0027$ & 0.1033 & 5.8 & $0.1199 \pm 0.0045$ & $-0.03737 \pm 0.00109$ \\
\hline 914.18007 & 27 & 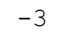 & $\mathrm{E}$ & 26 & -2 & $\mathrm{E}$ & 0.3401 & \pm 0.0085 & $0.1014 \pm 0.0026$ & $0.0936 \pm 0.0026$ & 0.0899 & 0 & $0.0998 \pm 0.0037$ & $-0.00678 \pm 0.00031$ \\
\hline 917.76754 & 35 & -3 & E & 34 & -2 & $\mathrm{E}$ & 0.2940 & \pm 0.0074 & $0.1080 \pm 0.0029$ & $0.0994 \pm 0.0027$ & 0.0935 & 5.9 & $0.1062 \pm 0.0040$ & $-0.00884 \pm 0.00035$ \\
\hline 920.11093 & 6 & 5 & E & 5 & 4 & E & 0.2446 & \pm 0.0061 & $0.0939 \pm 0.0025$ & $0.0948 \pm 0.0028$ & 0.0947 & 0.1 & $0.0941 \pm 0.0038$ & $-0.00742 \pm 0.00041$ \\
\hline 925.66545 & 35 & 4 & A2 & 34 & 3 & A1 & 0.2861 & \pm 0.0071 & $0.1053 \pm 0.0027$ & $0.0921 \pm 0.0023$ & .0924 & -0.3 & $0.1025 \pm 0.0035$ & $-0.00446 \pm 0.00020$ \\
\hline 927.41692 & 39 & 4 & A2 & 38 & 3 & A1 & 0.2540 & \pm 0.0064 & $0.1046 \pm 0.0029$ & $0.0893 \pm 0.0028$ & 0.0854 & 4.4 & $0.1014 \pm 0.0040$ & $-0.00185 \pm 0.00015$ \\
\hline
\end{tabular}




$\begin{array}{rccccccccccccccc}931.53130 & 13 & -6 & \mathrm{E} & 12 & -5 & \mathrm{E} & 0.3014 \pm 0.0075 & 0.1145 \pm 0.0028 & 0.0941 \pm 0.0023 & 0.0957 & -1.7 & 0.1102 \pm 0.0036 & -0.01125 & \pm 0.00177 \\ 940.57734 & 15 & 7 & \mathrm{~A} 2 & 14 & 6 & \mathrm{~A} 1 & 0.3310 \pm 0.0082 & 0.1171 \pm 0.0033 & 0.0968 \pm 0.0029 & 0.0949 & 2.0 & 0.1128 \pm 0.0044 & -0.00285 & \pm 0.00010 \\ 946.16162 & 27 & 7 & \mathrm{~A} 2 & 26 & 6 & \mathrm{~A} 1 & 0.3348 \pm 0.0082 & 0.1016 \pm 0.0027 & 0.0886 \pm 0.0023 & 0.0886 & 0.0 & 0.0989 \pm 0.0035 & -0.00218 \pm 0.00035 \\ 951.06367 & 38 & 7 & \text { A2 } & 37 & 6 & \text { A1 } & 0.2507 \pm 0.0062 & 0.0932 \pm 0.0026 & 0.0770 \pm 0.0022 & 0.0781 & -1.4 & 0.0898 \pm 0.0034 & -0.00804 \pm 0.00060\end{array}$

\section{Footnote:}

\section{(a) Line position (in $\mathrm{cm}^{-1}$ )}

(b) Upper state quantum numbers $J,(K \times \ell)$ product, Sym. $J$ and $K$ are the rotational quantum numbers and Sym stands for A1, A2 and E symmetry. $\ell$ is the quantum number associated to the vibrational angular momentum.

(c) Lower state quantum numbers $J,(K \times \ell)$ product, Sym.

(d) Measured self-broadening coefficients $\left(\mathrm{cm}^{-1} \mathrm{~atm}^{-1}\right)$ from Ref. [10].

(e) Measured $\mathrm{N}_{2}$-broadening coefficients $\left(\mathrm{cm}^{-1} \mathrm{~atm}^{-1}\right)$ from Ref. [10].

(f) Measured $\mathrm{O}_{2}$-broadening coefficients $\left(\gamma_{\text {mea }}\right.$ in $\left.\mathrm{cm}^{-1} \mathrm{~atm}^{-1}\right)$; uncertainties are calculated using Eq. (3).

(g) $\mathrm{O}_{2}$-broadening coefficients calculated $\left(\gamma_{\text {calc }}\right.$ in $\left.\mathrm{cm}^{-1} \mathrm{~atm}^{-1}\right)$ using Eq. (4) and the values of the coefficients involved listed in Table 3.

(h) Differences $\left[\left(\gamma_{\text {mea }}-\gamma_{\text {calc }}\right) / \gamma_{\text {mea }}\right] \times 100$ between the measured $\gamma_{\text {mea }}$ and calculated $\gamma_{\text {calc }} \mathrm{O}_{2}$-broadening coefficients.

(i) Air-broadening coefficients derived from the $\mathrm{N}_{2}$ - and $\mathrm{O}_{2}$-broadening coefficients and calculated using Eq. (5).

(j) $\mathrm{O}_{2}$-shift coefficients $\left(\delta^{0}\right.$ in $\left.\mathrm{cm}^{-1} \mathrm{~atm}^{-1}\right)$; uncertainties are calculated using Eq. (3). 
TABLE 3.

Best-fit coefficients $a_{J}^{0}$ and $a_{J}^{2}$ (in $\mathrm{cm}^{-1} \mathrm{~atm}^{-1}$ ) involved in Eq. (4) used to reproduce the measured $\mathrm{O}_{2}$ broadening parameters of the $\mathrm{v}_{6}$ band of $\mathrm{CH}_{3} \mathrm{I}$.

\begin{tabular}{lll}
\hline$J$ & $a_{J}^{0}$ & $a_{J}^{2}$ \\
\hline 5 & $0.1099(47)$ & $-0.000948(172)$ \\
6 & $0.1148(28)$ & $-0.000832(137)$ \\
7 & $0.1105(20)$ & $-0.000417(90)$ \\
8 & $0.1146(26)$ & $-0.000559(80)$ \\
9 & $0.1051(19)$ & $-0.000107(13)$ \\
10 & $0.1042(20)$ & $-0.000205(27)$ \\
11 & $0.1038(14)$ & $-0.000364(40)$ \\
12 & $0.0994(52)$ & $-0.000147(24)$ \\
13 & $0.1051(59)$ & $-0.000461(46)$ \\
14 & $0.0969(21)$ & $-0.000054(10)$ \\
15 & - & - \\
16 & $0.0993(33)$ & $-0.000326(36)$ \\
17 & $0.1008(32)$ & $-0.000023(3)$ \\
18 & $0.1004(62)$ & $-0.000391(52)$ \\
19 & $0.1017(7)$ & $-0.000610(73)$ \\
20 & $0.0999(25)$ & $-0.000139(15)$ \\
21 & $0.1040(33)$ & $-0.00172(16)$ \\
22 & $0.1035(26)$ & $-0.000341(28)$ \\
23 & $0.0981(21)$ & $-0.000351(25)$ \\
24 & - & - \\
25 & $0.1004(19)$ & $-0.000234(29)$ \\
26 & $0.0901(12)$ & $-0.000041(7)$ \\
27 & $0.0931(34)$ & $-0.000197(18)$ \\
& $0.0952(21)$ & $-0.000349(29)$ \\
\hline
\end{tabular}




$\begin{array}{lll}29 & 0.0864(12) & -0.000342(42) \\ 30 & - & - \\ 31 & 0.1162(51) & -0.000848(94) \\ 32 & 0.0953(16) & -0.000369(46) \\ 33 & 0.0857(28) & -0.000086(11) \\ 34 & 0.0944(34) & -0.000223(20) \\ 35 & 0.0974(20) & -0.000822(138) \\ 36 & 0.0858(28) & -0.000144(16) \\ 37 & 0.0849(12) & -0.000189(11) \\ 38 & 0.0858(19) & -0.000041(5) \\ 39 & 0.1037(39) & -0.000752(94) \\ 40 & 0.0815(17) & -0.000045(7) \\ 41 & 0.0914(24) & -0.000419(38) \\ 42 & 0.0851(23) & -0.000490(54) \\ 43 & 0.0911(6) & -0.000345(31) \\ 44 & 0.0885(6) & -0.000349(27) \\ 45 & 0.0918(17) & -0.000546(65) \\ 46 & 0.0893(22) & -0.000625(54) \\ 47 & 0.0811(14) & -0.000194(23) \\ 48 & 0.1062(54) & -0.00351(39 \\ 49 & 0.0765(10 & -0.000754(70) \\ & & \\ & & \\ 34 & \end{array}$

Note: Numbers between parentheses are the uncertainties $(1 \sigma)$ in the units of the last quoted digit. For each $J$ value, the number of $\mathrm{O}_{2}$-broadening coefficients used in the fit ranges between 4 and 11 . 


\section{TABLE 4.}

Statistical analysis of the fit to Eq. (4) of the measured $\mathrm{O}_{2}$ broadening coefficients of the $v_{6}$ band of $\mathrm{CH}_{3} \mathrm{I}\left(\delta=\left|\gamma_{\text {mea }}-\gamma_{\text {calc }}\right| / \gamma_{\text {mea }} \times 100\right)$.

\begin{tabular}{cc}
\hline $\begin{array}{c}\text { Number of lines } \\
\text { used in the fit }\end{array}$ & 263 \\
\hline $\mathrm{J}_{\max }$ & 49 \\
$\mathrm{~K}_{\max }$ & 6 \\
$0 \% \leq \delta<4 \%$ & $78.3 \%$ \\
$4 \% \leq \delta<7 \%$ & $17.1 \%$ \\
$7 \% \leq \delta<9 \%$ & $4.6 \%$ \\
\hline
\end{tabular}

